\title{
Oral L-arginine supplementation in cystic fibrosis patients: a placebo-controlled
} study

\author{
H. Grasemann*, C. Grasemann\#, F. Kurtz*, G. Tietze-Schillings`, U. Vester* and F. Ratjen*
}

ABSTRACT: Exhaled nitric oxide (eNO) is decreased in cystic fibrosis (CF). The effect of oral Larginine, the precursor of enzymatic nitric oxide (NO) formation, on airway NO in patients with CF was studied.

In a pilot study, oral L-arginine was given in a single dose of $200 \mathrm{mg} \cdot \mathrm{kg}^{-1}$ body weight to eight healthy controls and eight CF patients. Subsequently, the same L-arginine dose was given to 10 patients with CF (five females) t.i.d. for 6 weeks in a randomised double-blind placebo-controlled crossover study.

A single dose of oral L-arginine resulted in a 5.5-fold increase of L-arginine in plasma and a 1.3fold increase of L-arginine in sputum after $2 \mathrm{~h}$. Maximum eNO, within $3 \mathbf{~ h}$ of L-arginine intake, increased significantly in both CF patients $(5.4 \pm 2.1 \mathrm{ppb}$ versus $8.3 \pm 3.5 \mathrm{ppb})$ and controls (18.0 \pm 8.1 ppb versus $26.4 \pm 12.3 \mathrm{ppb})$. Supplementation of L-arginine for 6 weeks resulted in a sustained increase in eNO compared to placebo (9.7 $\pm 5.7 \mathrm{ppb}$ versus $6.3 \pm 3.1 \mathrm{ppb})$. An effect of L-arginine supplementation on forced expiratory volume in one second was not observed.

These data indicate that airway nitric oxide formation in cystic fibrosis patients can be augmented with oral L-arginine supplementation.

\section{KEYWORDS: Cystic fibrosis, L-arginine, lung function, nitric oxide}

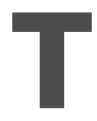
he amino acid L-arginine is the precursor for enzymatic nitric oxide (NO) synthesis. NO synthases (NOSs) have been shown to be involved in regulatory processes in the lung including inflammation, host defense and bronchomotor control. The fraction of exhaled NO (eNO) has been found to be reduced in patients with cystic fibrosis (CF) compared to healthy individuals [1]. The mechanisms that lead to low airway NO in CF are not completely understood but may include mechanical retention of NO in airway secretions, conversion of $\mathrm{NO}$ to metabolites, and consumption of NO by denitrifying bacteria [2]. Whilst limited evidence would support all of these concepts, there is also evidence for reduced enzymatic formation of $\mathrm{NO}$ in CF, whereby blood or tissue levels of L-arginine may become rate limiting for $\mathrm{NO}$ synthesis [3, 4].

The bronchodilatatory effect of $\mathrm{NO}$ (in ppm concentrations) is well known [5-7], and recent research in animals suggests a causal relationship between airway NOS activity and bronchomotor tone in CF. In these experiments, the addition of L-arginine resulted in a significant increase of electrical field stimulated relaxation of isolated tracheas from mice deficient for the cystic fibrosis transmembrane conductance regulator (CFTR) protein but not from wild-type animals [8]. In cross-sectional studies in CF patients, a positive correlation was observed between pulmonary function and both eNO [1, 9, 10] and NO metabolite concentration in sputum [11], suggesting that pulmonary function is reduced in $\mathrm{CF}$ patients with decreased airway $\mathrm{NO}$ formation. This view is supported by the recent observation that variants in the neuronal NOS gene (NOS1), that are associated with low eNO, seem to predispose to a more rapid decline in pulmonary function in children with CF [12].

In previous studies, the current authors demonstrated that neither inhalation of NO-containing gas nor infusion of L-arginine had an effect on pulmonary function in $\mathrm{CF}$ patients. However, a single dose of i.v. L-arginine in a dose of $500 \mathrm{mg} \cdot \mathrm{kg}^{-1}$ body weight resulted in a significant increase of eNO in these patients [13, 14]. Oral Larginine in doses of $100 \mathrm{mg} \cdot \mathrm{kg}^{-1}$ and $200 \mathrm{mg} \cdot \mathrm{kg}^{-1}$ body weight had been shown to increase eNO in healthy human subjects [15]. The effect of oral L-arginine supplementation in CF patients has, to the present authors' knowledge, not been

\section{AFFILIATIONS}

*Children's Hospital

\#Dept of Human Genetics

-Dept of Pharmacy, University of

Duisburg-Essen, Essen, Germany.

CORRESPONDENCE

H. Grasemann

Children's Hospital

University of Essen

Hufeland Str. 55

D-45122 Essen

Germany

Fax: 492017235983

E-mail: hartmutg@hotmail.com

Received:

July 212004

Accepted after revision:

September 12004

SUPPORT STATEMENT

This study was supported by

Mukoviszidose e.V. 
studied. The current authors speculated that augmentation of airway NO formation by oral supplementation of L-arginine could have a positive effect on airway NO formation and pulmonary function in these patients. Therefore, the present authors studied the effect of a single dose of oral L-arginine on eNO and a 6-week supplementation of oral L-arginine in a dose of $200 \mathrm{mg} \cdot \mathrm{kg}^{-1}$ body weight t.i.d. on $\mathrm{eNO}$ and pulmonary function in patients with CF in a randomised double-blind placebo-controlled study.

\section{PATIENTS AND METHODS}

The diagnosis of $\mathrm{CF}$ in participating patients had been confirmed by repeated sweat tests with chloride concentrations $>60 \mathrm{mmol} \cdot \mathrm{L}^{-1}$, and by mutation analysis of the CFTR gene. Written informed consent was obtained from each patient, and/or their parents, respectively. The study was approved by the institutional review board of the University of Essen, Essen, Germany.

\section{Single dose experiments}

Subjects

Eight patients (five females) with CF were included in this part of the study. Mean age was 22 yrs (range 14-37 yrs), mean \pm SD forced vital capacity (FVC) was $68.0 \pm 14.5 \%$ (range $50-91 \%$ ) and mean forced expiratory volume in one second (FEV1) was $41.8 \pm 21.3 \%$ (range $22-75 \%$ ) of predicted values. Seven patients had chronic colonisation of the airways with Pseudomonas aeruginosa and one was colonised with Staphlococcus aureus. None of the patients received systemic or inhaled corticosteroids at the time of study. All patients included were in a clinically stable condition. CF patients were compared to eight (five females) healthy nonsmoking controls with a mean age of 28 yrs (range 23-44 yrs), who had no history of asthma or atopy, and had no symptoms of upper or lower airway infection at the time of study.

\section{Study design}

L-arginine (Synopharm, Barsbüttel, Germany) was diluted with indifferent viscous flavouring solution to a $10 \%$ L-arginine solution. This solution was bottled and kept refrigerated until it was used. At the time of study each subject ingested the $10 \%$ L-arginine solution in a dose of $200 \mathrm{mg}$ of L-arginine per $\mathrm{kg}$ body weight, diluted with orange juice to a total volume of $\sim 250 \mathrm{~mL}$.

Measurements of nasal $\mathrm{NO}$, eNO and blood sampling were performed at baseline as well as 60,120 and $180 \mathrm{~min}$ following the intake of L-arginine. Blood was collected in EDTA containing $2.7 \mathrm{~mL}$ tubes by venipuncture for the measurement of plasma amino acid and urea concentrations in all subjects. Spontaneously expectorated sputum was collected before and $120 \mathrm{~min}$ after L-arginine intake in all but two patients, who were unable to expectorate sputum.

\section{Double-blind placebo-controlled trial}

Patients

A total of 11 patients (five females) with confirmed diagnosis of CF were included in this study. Mean age was 24 yrs (range $15-41$ yrs), mean \pm SD FVC $75.1 \pm 29.4 \%$ (range $40-125 \%$ ) and mean FEV1 $58.8 \pm 33.1 \%$ (range $25-127 \%$ ) of predicted values. All patients had chronic airway infection with $P$. aeruginosa. None of the patients received systemic or inhaled corticosteroids at the time of study. All patients included were in a clinically stable condition after a 2-week treatment period with i.v. antibiotics.

\section{Study design}

The study was conducted in a randomised double-blind crossover design. Patients were either treated with $200 \mathrm{mg} \cdot \mathrm{kg}^{-1}$ body weight t.i.d. of oral L-arginine for 6 weeks followed by 6 weeks of placebo or vice versa. Measurements of nasal and eNO, as well as pulmonary function, were performed at baseline and after each 6-week treatment period. Study visits were scheduled in the morning and measurements were performed prior to L-arginine and placebo intake that day, respectively.

\section{Pulmonary function measurements}

Pulmonary function tests were performed with a bell-spirometer (Volugraph, Mijnhardt, Bunnik, the Netherlands). Results were expressed as percentages of normal reference values $[16,17]$.

\section{Nitric oxide measurements}

NO measurements were performed according to published ATS and ERS standards [18, 19]. NO was measured with a chemiluminescence analyser (NOA 280; Sievers, Boulder, CO, USA). Nasal NO measurements were performed as recently published $[18,20]$. Briefly, air from total lung capacity had to be exhaled orally against a flow restrictor to generate a mouth pressure exceeding $5 \mathrm{~cm}$ of $\mathrm{H}_{2} \mathrm{O}$ for soft palate closure. Air was aspirated from one nostril through a tight fitting nasal olive at a constant sample flow of $50 \mathrm{~mL} \cdot \mathrm{s}^{-1}$ generated by an external pump. The other nostril was left open or, at room NO concentrations $>10 \mathrm{ppb}$, connected to a reservoir of NO-free air. The mean of two NO plateau measurements for each nostril was used for data analysis. Exhaled NO was measured using single breath on-line measurements for the assessment of lower airway NO [18, 19]. Measurements of eNO were performed at a constant expiratory flow of $3 \mathrm{~L} \cdot \mathrm{min}^{-1}$. The mean value of three end-expiratory NO levels was calculated for each subject.

\section{Plasma amino acids}

Plasma samples were deproteinised within $30 \mathrm{~min}$ of collection. Amino acids were determined by ion exchange chromatography (IEC) on an amino acid analyser LC 3000 (Eppendorf, Hamburg, Germany) according to the manufacturer's specifications. Sputum samples were diluted 1:1 with buffer, vortexed for $2 \mathrm{~min}$ followed by $10 \mathrm{~min}$ of centrifugation at $1,000 \mathrm{~g}$ for $10 \mathrm{~min}$. Clear supernatant was used for the amino acid IEC.

\section{Statistical analysis}

Data were expressed as mean $\pm \mathrm{SD}$. Comparisons between groups were made by t-test, after testing for normal distribution by Kolmogorov-Smirnov test. Intragroup comparisons were performed with paired t-tests.

\section{RESULTS}

\section{Single L-arginine dose}

Baseline plasma concentrations of the amino acids L-arginine, citrulline, and ornithine, and plasma urea did not differ 
between CF patients and controls. A single dose of oral Larginine $\left(200 \mathrm{mg} \cdot \mathrm{kg}^{-1}\right.$ body weight) resulted in a significant increase of plasma L-arginine concentrations in both $\mathrm{CF}$ patients and healthy controls. Plasma levels of citrulline, the product of L-arginine conversion by NO synthases, did not increase after oral L-arginine. Plasma levels of ornithine and urea, which are products of L-arginine metabolism by arginases, increased significantly in CF. A significant increase in plasma ornithine but not urea was seen in the controls (table 1, fig. 1). Plasma L-arginine and ornithine concentrations were significantly greater in $\mathrm{CF}$ than in controls $2 \mathrm{~h}$ after L-arginine ( $\mathrm{p}=0.05$, respectively; fig. 1 ). Mean concentration of L-arginine in CF sputum increased significantly $2 \mathrm{~h}$ after oral Larginine (11.7 versus $15.1 \mathrm{nmol} \cdot \mathrm{mL}^{-1}, \mathrm{p}=0.027$; fig. 2$)$, while concentrations of ornithine (35.6 versus $32.3 \mathrm{nmol} \cdot \mathrm{mL}^{-1}, \mathrm{p}=0.2$ ) and citrulline (36.2 versus $34.1 \mathrm{nmol} \cdot \mathrm{mL}^{-1}, \mathrm{p}=0.2$ ) remained unchanged.

Mean eNO at baseline was $15.0 \pm 8.1 \mathrm{ppb}$ in controls and $5.4 \pm 2.1 \mathrm{ppb}$ in $\mathrm{CF}$ patients $(\mathrm{p}=0.006)$, confirming previous findings of decreased airway NO formation in CF. Similarly, nasal NO at baseline was significantly lower in CF patients than in controls $(62.4 \pm 39.7 \mathrm{ppb}$ versus $158.6 \pm 43.4 \mathrm{ppb}$, $\mathrm{p}<0.001)$. A single dose of $\mathrm{L}$-arginine resulted in a significant increase in eNO after 1,2 , and $3 \mathrm{~h}$ in the controls $(\mathrm{p}<0.01$, respectively). In the $\mathrm{CF}$ patients there was considerable variability in the course of eNO after oral L-arginine. Mean eNO at the given time-points did not increase significantly $(6.5 \pm 2.2 \mathrm{ppb}, \mathrm{p}=0.06$ at $1 \mathrm{~h}$; table 2 and fig. 3$)$. However, the maximal \pm SD increase of eNO within $3 \mathrm{~h}$ after oral L-arginine in the CF patients was statistically significant $(1.7 \pm 0.9$-fold, $\mathrm{p}=0.02)$ and was comparable to the maximal increase of eNO in the controls ( $1.8 \pm 0.5$-fold, $\mathrm{p}=0.001$; table 2 and fig. 4$)$.

Mean nasal NO concentrations did not change significantly after a single dose of L-arginine in controls and CF patients at the given time-points, but the maximal $\pm S D$ increase of nasal $\mathrm{NO}$ was $1.3 \pm 0.5$ fold $(\mathrm{p}=0.03)$ in controls and $1.2 \pm 0.2$ fold $(\mathrm{p}=0.08)$ in CF (table 2, fig. 5).

\section{Double-blind placebo-controlled trial}

L-arginine was well tolerated in all patients but one, who acquired airway infection with Burkholderia cepacia, which was successfully eradicated with i.v. antibiotic treatment. This patient was excluded from the final analysis.
Of the 10 patients who finished the study, five took L-arginine for 6 weeks followed by 6 weeks of placebo and five started with placebo followed by L-arginine supplementation.

Mean eNO at baseline (after 14 days of i.v. antibiotics) was $11.4 \pm 6.0 \mathrm{ppb}$. After 6 weeks of L-arginine eNO was $9.7 \pm$ $5.7 \mathrm{ppb}$, which was not significantly different from baseline. After 6 weeks of placebo eNO declined to $6.3 \pm 3.1 \mathrm{ppb}$ which was significantly lower than eNO at baseline $(p=0.001)$ and after L-arginine supplementation $(\mathrm{p}=0.03$; fig. 6).

The decline of FEV1 from baseline $(58.8 \pm 33.1 \%$ predicted $)$ was similar after L-arginine treatment $(54.5 \pm 32.9 \%$ predicted, $\mathrm{p}=0.04)$ and placebo $(53.4 \pm 31.8 \%$ predicted, $\mathrm{p}=0.01)$. Quantitative sputum counts in eight CF patients were not different after 6 weeks of L-arginine or placebo (data not shown).

\section{DISCUSSION}

The present study confirmed that airway NO levels are decreased in CF patients compared to healthy controls. Oral L-arginine given in a single dose of $200 \mathrm{mg} \cdot \mathrm{kg}^{-1}$ body weight resulted in a small but statistically significant increase of lower airway NO formation in patients with $\mathrm{CF}$. This increase in eNO was smaller in CF than in healthy controls treated with the same dose of L-arginine, although the increase in L-arginine plasma levels after application was not reduced in CF patients. The current authors further demonstrated that oral L-arginine given in the same dose t.i.d. for 6 weeks had a sustained effect on eNO in CF patients, preventing the decline of eNO from baseline values obtained after i.v. antibiotic treatment.

It is now widely accepted that $\mathrm{NO}$ formation in the upper and lower airways is decreased in CF [1, 2, 21, 22], and the results from the present study confirm these findings. The reasons for decreased NO formation in CF are not completely understood, but studies in mouse models and in patients with CF have found that the expression of the inducible isoform of $\mathrm{NO}$ synthases (NOS2) is decreased or absent in CF airways [3, 4, 22]. Recent evidence suggests that this decrease in NOS2 expression parallels the neutrophil dominated airway inflammation in CF. WOOLDRIDGE et al. [22] have studied NOS2 expression by immunohistochemistry and found decreasing expression of NOS2 with increasing concentrations of inflammatory markers, such as interleukin- 8 and the number of neutrophils in CF BAL fluid in different cell types from the

\begin{tabular}{|c|c|c|c|c|c|c|}
\hline & \multicolumn{3}{|c|}{ CF patients ${ }^{\#}$} & \multicolumn{3}{|c|}{ Controls $^{\#}$} \\
\hline & $60 \mathrm{~min}$ & $120 \mathrm{~min}$ & $180 \mathrm{~min}$ & $60 \mathrm{~min}$ & $120 \mathrm{~min}$ & $180 \mathrm{~min}$ \\
\hline L-arginine & $5.1 \pm 2.6^{\star *}$ & $5.5 \pm 2.3^{\star \star}$ & $3.8 \pm 2.0^{* *}$ & $2.7 \pm 0.3^{* \star}$ & $3.0 \pm 0.8^{\star *}$ & $2.4 \pm 0.6^{* *}$ \\
\hline Urea & $1.2 \pm 0.1^{*}$ & $1.3 \pm 0.1^{\star *}$ & $1.4 \pm 0.4$ & $1.0 \pm 0.03$ & $1.0 \pm 0.03$ & $1.0 \pm 0.07$ \\
\hline
\end{tabular}

Data are presented as mean \pm SD. CF: cystic fibrosis. ${ }^{*}: n=8 .{ }^{*}: p<0.05 ;{ }^{*}: p<0.01$. 

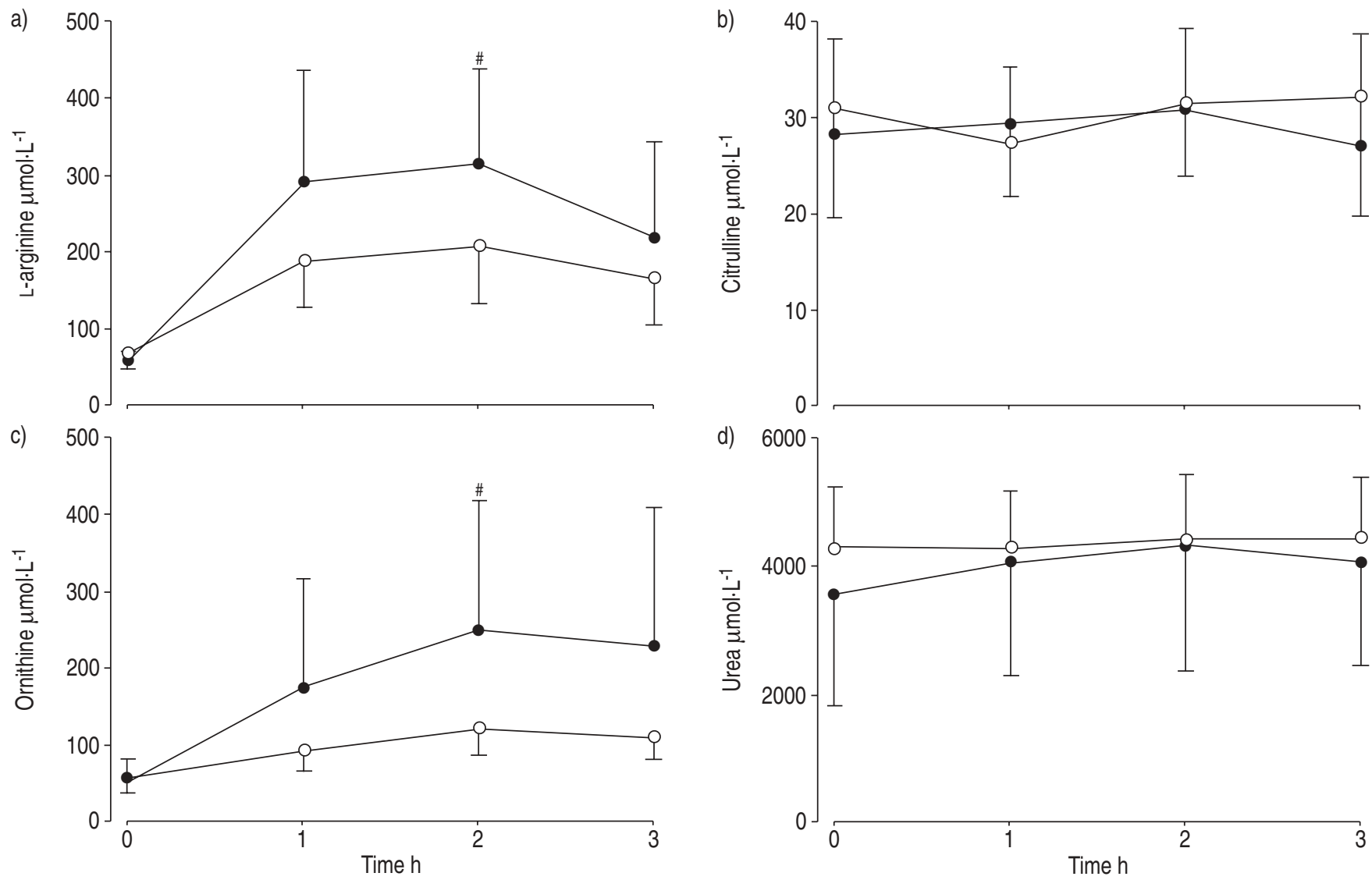

FIGURE 1. Plasma concentrations of a) L-arginine, b) citrulline c) ornithine and d) urea before and after a single dose of oral L-arginine (200 $\mathrm{mg} \mathrm{kg}^{-1} \mathrm{body}$ weight) in eight cystic fibrosis patients $(\bullet)$ and eight controls $(\bigcirc)$. Data are presented as mean \pm SD. $\#: p=0.05$.

airways. This effect of inflammation on NOS2 expression is in contrast to other inflammatory airway conditions, such as asthma, but could explain the interesting observation that eNO in CF patients increases when treated with antibiotics although a reduction of denitrifying organisms in the CF airways may also contribute to the increase in eNO during antibiotic

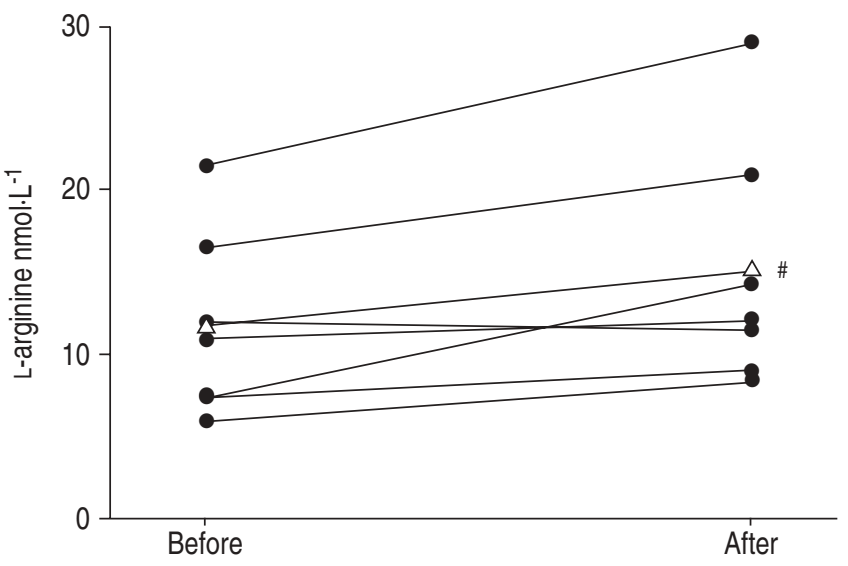

FIGURE 2. Individual L-arginine concentrations in the sputum of seven cystic fibrosis patients before and $2 \mathrm{~h}$ after a single dose of oral L-arginine $\left(200 \mathrm{mg} \cdot \mathrm{kg}^{-1}\right.$ body weight). $\Delta$ : mean sputum L-arginine concentrations. $\#$ : $p=0.025$. treatment $[23,24]$. In accordance with this observation, eNO in the $\mathrm{CF}$ patients participating in the present study was significantly lower after 6 weeks of placebo, compared to

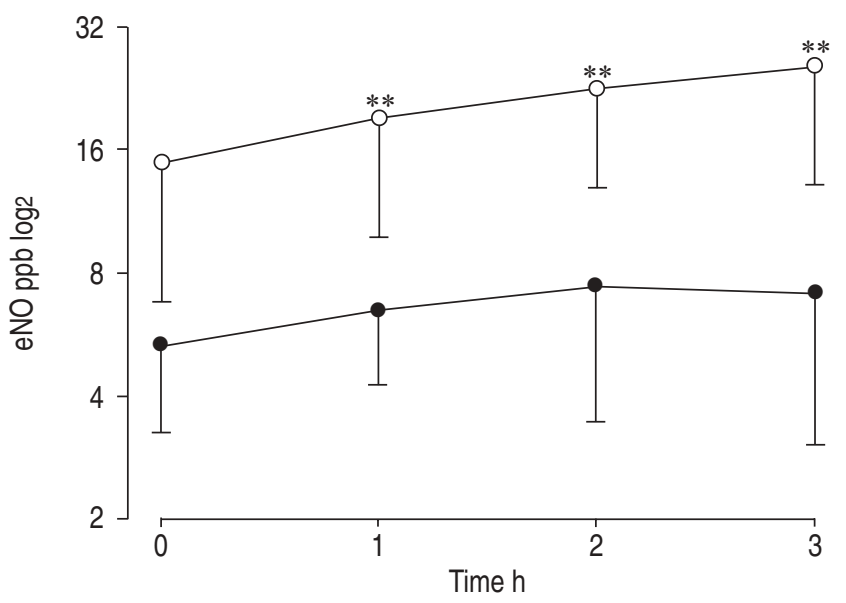

FIGURE 3. Mean fraction of exhaled nitric oxide (eNO) in parts per billion (ppb) before and after a single dose of oral L-arginine (200 $\mathrm{mg} \cdot \mathrm{kg}^{-1}$ body weight) in eight cystic fibrosis (CF) patients $(\bullet$ ) and eight controls $(O)$. The increase in mean eNO in the CF patients was not significantly significant at these time points. Data are presented as mean $\pm S D$. ${ }^{* *}: p<0.01$ versus respective time point for $C F$ patients. 


\begin{tabular}{|c|c|c|c|c|c|c|c|c|}
\hline & \multicolumn{4}{|c|}{ CF patients ${ }^{\#}$} & \multicolumn{4}{|c|}{ Controls ${ }^{\#}$} \\
\hline & $60 \mathrm{~min}$ & $120 \mathrm{~min}$ & $180 \mathrm{~min}$ & Maximum & $60 \mathrm{~min}$ & $120 \mathrm{~min}$ & $180 \mathrm{~min}$ & Maximum \\
\hline eNO & $1.3 \pm 0.7$ & $1.6 \pm 1.0$ & $1.4 \pm 0.7$ & $1.7 \pm 0.9^{*}$ & $1.3 \pm 0.3^{\star *}$ & $1.7 \pm 0.6^{\star \star}$ & $1.8 \pm 0.4^{\star *}$ & $1.8 \pm 0.5^{\star \star}$ \\
\hline
\end{tabular}

Data are presented as mean $\pm \mathrm{SD}$. Maximum is the maximal increase in eNO within $3 \mathrm{~h}$ of oral L-arginine intake. ${ }^{*}: \mathrm{n}=8 .{ }^{*}: \mathrm{p}<0.05 ;{ }^{*}: \mathrm{p}<0.01$

baseline values after 2 weeks of $i . v$. antibiotic treatment. Of interest, 6 weeks of oral L-arginine resulted in a significantly

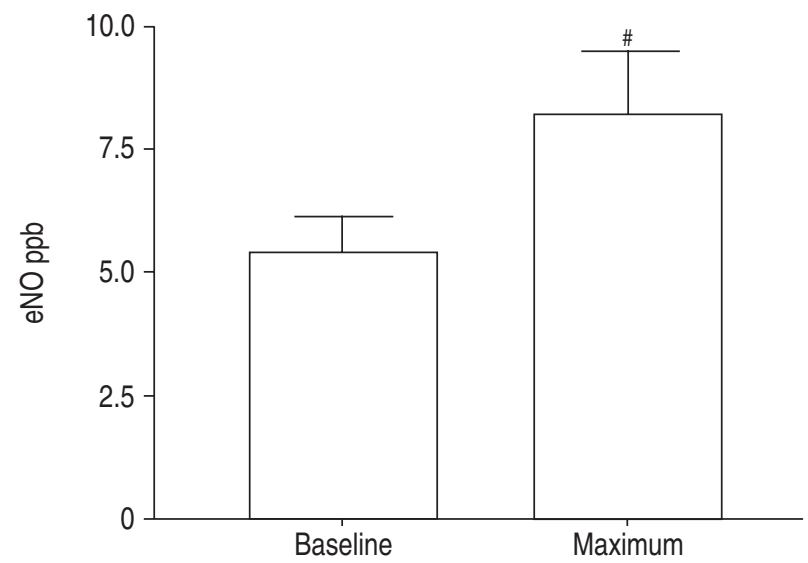

FIGURE 4. Mean fraction of exhaled nitric oxide (eNO) in parts per billion (ppb) before (baseline) and at mean maximum eNO within $3 \mathrm{~h}$ after a single dose of oral Larginine (200 $\mathrm{mg} \cdot \mathrm{kg}^{-1}$ body weight) in eight patients with cystic fibrosis. ${ }^{*}: \mathrm{p}=0.02$.

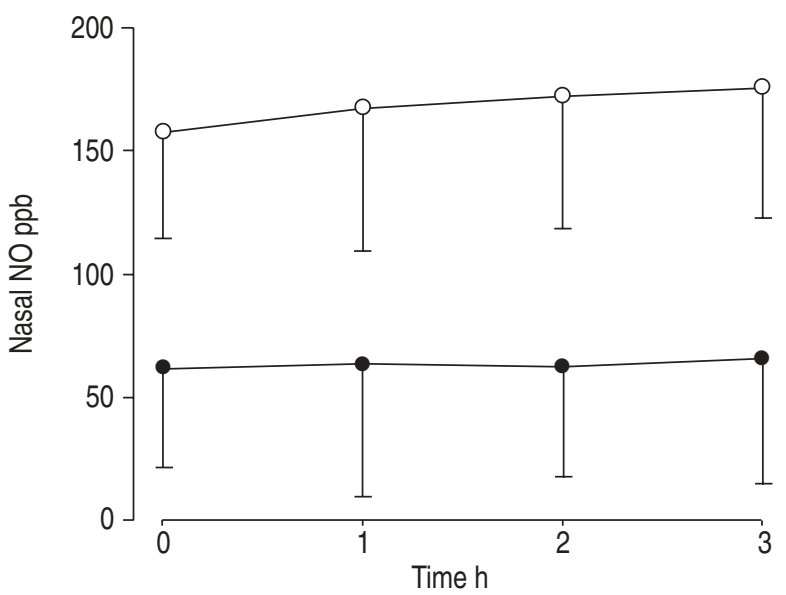

FIGURE 5. Mean nasal nitric oxide (NO) in parts per billion (ppb) before and after a single dose of oral L-arginine (200 $\mathrm{mg} \cdot \mathrm{kg}^{-1}$ body weight) in eight cystic fibrosis patients $(\bullet)$ and eight controls $(\bigcirc)$. Nasal NO did not change significantly in either study group. Data are presented as mean $\pm \mathrm{SD}$. higher eNO than treatment with placebo, and was not different from the eNO after i.v. antibiotic treatment, thus the expected decrease of eNO after discontinuation of antibiotic treatment could sufficiently be prevented by L-arginine supplementation. It is important to mention here, that eNO in the current study was measured $12 \mathrm{~h}$ after the last intake of L-arginine, suggesting a sustained effect of long-term supplementation of L-arginine on airway NO formation.

The single dose experiments showed that the increase in plasma L-arginine was only transient since plasma levels peaked after $2 \mathrm{~h}$ and had already returned to baseline after $3 \mathrm{~h}$. However, the increased eNO after 6 weeks of L-arginine supplementation was measured $12 \mathrm{~h}$ after the last L-arginine intake. Possible explanations for this sustained effect are that Larginine supplementation may have resulted in accumulation of L-arginine or of nitrogen oxides stored in airway secretions and thus in either a longer lasting substrate availability for $\mathrm{NO}$ synthesis from NOS or lasting NO formation from nitrogen oxides.

Another explanation for the observed sustained increase in eNO is that the 6 week L-arginine supplementation may have resulted in an increase of NOS expression in CF airways. Indeed, an increase in L-arginine concentration may augment NO formation from NOS by two independent mechanisms.

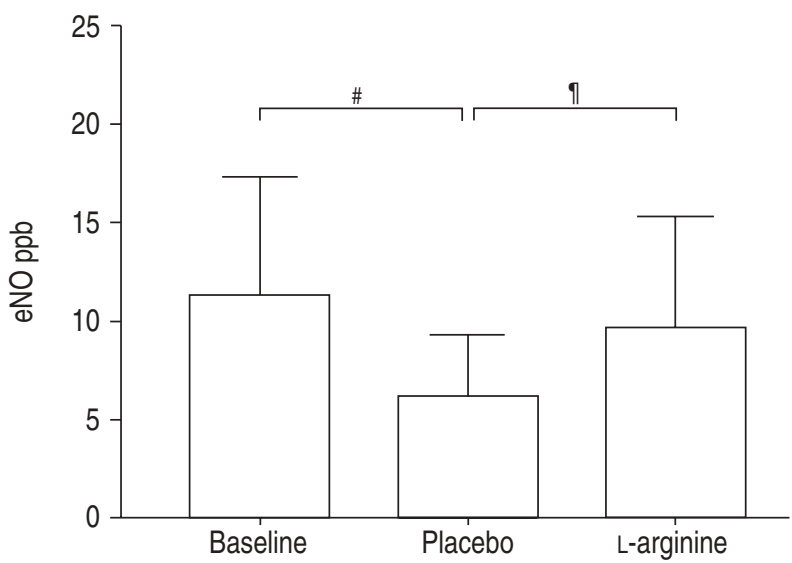

FIGURE 6. Mean fraction of exhaled nitric oxide (eNO) in parts per billion (ppb) in 10 patients with cystic fibrosis at baseline and after 6 weeks of oral L-arginine (200 mg $\cdot \mathrm{kg}^{-1}$ body weight t.i.d.) or corresponding placebo. eNO was significantly decreased after placebo but not after L-arginine supplementation. Data are presented as mean \pm SD. ${ }^{\#}: p=0.001 ;{ }^{\natural}: p=0.03$. 
One mechanism can be simply explained by increased L-arginine conversion in the setting of increased substrate availability. The other is an effect of extracellular L-arginine levels on cellular expression of NOS. This effect has recently been observed in in vitro experiments with stimulated astrocytes in cell culture. In these experiments adding increasing doses of L-arginine to the culture supernatant resulted in a dose dependent increase of NOS2 expression [25].

Taking into account the above mentioned effect of extracellular L-arginine concentration on NOS2 expression, it is quite conceivable that low airway $\mathrm{NO}$ formation in $\mathrm{CF}$ results from reduced bioavailability of L-arginine, the precursor of enzymatic NO formation from NOS. No differences were found in plasma L-arginine concentrations between clinically stable CF patients and healthy controls at baseline, which confirmed previous findings $[14,22]$. The larger increase in ornithine concentration in plasma at $2 \mathrm{~h}$ after a single dose of L-arginine in CF patients compared to controls $(p=0.05)$ could result from the fact that peak L-arginine levels at that time were also higher than in controls. Alternatively, this finding may suggest that the activity of arginases is increased in CF. Arginases are enzymes that metabolise L-arginine to form ornithine and urea. The expression of arginases seems to be increased in inflammatory airway conditions such as asthma [26, 27]. Arginases and NOS compete for their common substrate Larginine, and a shift of balance towards the expression of arginases, for instance during phases of infection or increased inflammation, could reduce the bioavailability of L-arginine for NOS and thus result in a down-regulation of NOS2 expression. However, NOS2 expression or arginase activity was not measured in this study. Further studies are needed to elucidate the role of arginases for L-arginine homeostasis in CF.

NOS is involved in a variety of processes in the lung including regulation of vascular muscle tone, bronchomotor control, host defense and inflammation $[5,28]$. Low airway $\mathrm{NO}$ formation in CF beneficially effects the colonisation of CF airways with certain pathogens, as suggested by the observation that certain variants in the genes encoding for the constitutive NOS isoforms NOS1 and NOS3 are associated with lower eNO and an increased rate of $P$. aeruginosa colonisation in $\mathrm{CF}$ $[29,30]$. The role of $\mathrm{NO}$ in the defense against Pseudomonas has also been demonstrated in in vitro experiments in which the NO donor, sodium nitroprusside, induced a dose dependent killing of $P$. aeruginosa [3]. However, these experiments were performed with a cultured Pseudomonas strain, and it is unclear whether increased NO formation in CF airways would also have a measurable effect on Pseudomonas growth in chronically infected airways. In contrast, L-arginine may have a positive effect on Pseudomonas growth since Pseudomonas uses Larginine as a substrate. In the current study, differences were not seen in quantitative $P$. aeruginosa sputum counts between 6 weeks of L-arginine supplementation and placebo.

Decreased NO formation may also have a negative effect on CF pulmonary function independent of airway colonisation. In experiments with mice it was shown, that the addition of Larginine resulted in a significant increase of isolated trachea relaxation from mice deficient for the CFTR protein but not from wild-type animals [8]. In humans, a positive correlation was observed between pulmonary function and both eNO
$[1,9,10]$ and NO metabolite concentrations in sputum [11] suggesting that pulmonary function is better in CF patients with higher airway NO formation. In addition, variants in the neuronal NOS gene (NOS1) associated with low eNO seem to predispose to a more rapid decline in pulmonary function in children with CF [12]. These data suggest that NO deficiency may, at least in part, contribute to airway obstruction in CF and that augmentation of $\mathrm{NO}$ synthesis could have a beneficial effect on pulmonary function in these patients. However, the present authors did not observe a positive effect of oral Larginine supplementation on pulmonary function, measured by spirometry, despite the positive effect on eNO, supporting previous papers showing that concentrations of $\mathrm{NO}$ in the low ppb range are not relevant to lung function in CF $[13,14]$. This lack of effect may, at least in part, also be related to the relatively small study population and to study design. The time point of the initiation of L-arginine supplementation may be critical since its effects may differ if started directly after i.v. treatment as compared to a later time point, when infection and inflammation are not suppressed by antibiotic treatment and airway NO formation may be further down-regulated.

In the single dose experiments, maximum nasal nitric oxide increased significantly in controls and a similar tendency was also observed in cystic fibrosis patients. The increase in nasal nitric oxide was less pronounced than seen in a previous study by the current authors using $500 \mathrm{mg} \cdot \mathrm{kg}^{-1}$ body weight $\mathrm{L}^{-}$ arginine i.v., which is probably related to the lower dose used in the present study [14]. The major source of nitric oxide in the upper airway is the paranasal sinuses where the highest concentrations of nitric oxide have been measured [31]. In cystic fibrosis, mucous obstruction results in poor communication of the paranasal sinuses with the nasal cavity and increases in nitric oxide production in the sinuses may not be detected by nasal nitric oxide measurements in these patients.

\section{ACKNOWLEDGEMENTS}

The authors would like to thank the patients for their participation, as well as M. Groch and B. Cirkel for technical assistance.

\section{REFERENCES}

1 Grasemann H, Michler E, Wallot M, Ratjen F. Decreased concentration of exhaled nitric oxide (NO) in patients with cystic fibrosis. Pediatr Pulmonol 1997; 24: 173-177.

2 Grasemann H, Ratjen F. Cystic fibrosis lung disease: the role of nitric oxide. Pediatr Pulmonol 1999; 28: 442-448.

3 Kelly TJ, Drumm ML. Inducible nitric oxide synthase expression is reduced in cystic fibrosis murine and human airway epithelial cells. J Clin Invest 1998; 102: 1200-1207.

4 Meng QH, Springall DR, Bishop AE, et al. Lack of inducible nitric oxide synthase in bronchial epithelium: a possible mechanism of susceptibility to infection in cystic fibrosis. $J$ Pathol 1998; 184: 323-331.

5 Barnes PJ, Belvisi MG. Nitric oxide and lung disease. Thorax 1993; 48: 1034-1043.

6 Högman M, Frostell CG, Hedenstrom H, Hedenstierna G. Inhalation of nitric oxide modulates adult human bronchial tone. Am Rev Respir Dis 1993; 148: 1474-1478. 
7 Lundberg JO, Settergren G, Gelinder S, Lundberg JM, Alving K, Weitzberg E. Inhalation of nasally derived nitric oxide modulates pulmonary function in humans. Acta Physiol Scand 1996; 158: 343-347.

8 Mhanna MJ, Ferkol T, Martin RJ, et al. Nitric oxide deficiency contributes to impairment of airway relaxation in cystic fibrosis mice. Am J Respir Cell Mol Biol 2001; 24: 621-626.

9 Ho LP, Innes JA, Greening AP. Exhaled nitric oxide is not elevated in the inflammatory airways diseases of cystic fibrosis and bronchiectasis. Eur Respir J 1998; 12: 1290-1294.

10 Grasemann H, Lax H, Treseler JW, Colin AA. Dornase alpha and exhaled NO in cystic fibrosis. Pediatr Pulmonol 2004; 38: 379-385.

11 Grasemann H, Ioannidis I, Tomkiewicz RP, de Groot H, Rubin BK, Ratjen F. Nitric oxide metabolites in cystic fibrosis lung disease. Arch Dis Child 1998; 78: 49-53.

12 Texereau J, Marullo S, Hubert D, et al. Nitric oxide synthase 1 as a potential modifier gene of decline in lung function in patients with cystic fibrosis. Thorax 2004; 59: 156-158.

13 Ratjen F, Gärtig S, Wiesemann HG, Grasemann H. Effect of inhaled nitric oxide on pulmonary function in cystic fibrosis. Respir Med 1999; 93: 579-583.

14 Grasemann H, Gärtig SS, Wiesemann HG, Teschler H, Konietzko N, Ratjen F. Effect of L-arginine infusion on exhaled nitric oxide in ciliary dyskinesia syndrome and cystic fibrosis. Eur Respir J 1999; 13: 114-118.

15 Kharitonov SA, Lubec G, Lubec B, Hjelm M, Barnes PJ. Larginine increases exhaled nitric oxide in normal human subjects. Clin Sci (Lond) 1995; 88: 135-139.

16 Zapletal A, Samanek M, Paul T. Lung function in children and adolescents. Methods, reference values. Prog Respir Res 1987; 22: 1-220.

17 Quanjer PH, Tammeling GJ, Cotes JE, Pedersen OF, Peslin R, Yernault JC. Lung volumes and forced ventilatory flows. Eur Resp J 1993; 6: Suppl. 6, 5-40.

18 Baraldi E, de Jongste JC. Measurement of exhaled nitric oxide in children, 2001. Eur Respir J 2002; 20: 223-237.

19 American Thoracic Society. Recommendations for standardized procedures for the on-line and off-line measurement of exhaled lower respiratory nitric oxide and nasal nitric oxide in adults and children - 1999. Am J Respir Crit Care Med 1999; 160: 2104-2117.
20 Grasemann H, Storm van's Gravesande K, Gärtig S, et al. Nasal nitric oxide levels are associated with a polymorphism in the neuronal nitric oxide synthase (NOS1) genes in cystic fibrosis patients. Nitric Oxide 2002; 6: 236-241.

21 Balfour-Lynn IM, Laverty A, Dinwiddie R. Reduced upper airway nitric oxide in cystic fibrosis. Arch Dis Child 1996; 75: 319-322.

22 Wooldridge JL, Deutsch GH, Sontag MK, et al. NO pathway in CF and non-CF children. Pediatr Pulmonol 2004; 37: 338-350.

23 Gaston B, Ratjen F, Vaughan JW, et al. Nitrogen redox balance in the cystic fibrosis airway: effects of antipseudomonal therapy. Am J Respir Crit Care Med 2002; 165: 387-390.

24 Jaffé A, Slade G, Rae J, Laverty A. Exhaled nitric oxide increases following admission for intravenous antibiotics in children with cystic fibrosis. J Cystic Fibrosis 2003; 2: 143-147.

25 Lee J, Ryu H, Ferrante RJ, Morris SM Jr, Ratan RR. Translational control of inducible nitric oxide synthase expression by arginine can explain the arginine paradox. Proc Natl Acad Sci USA 2003; 100: 4843-4848.

26 Meurs H, Maarsingh H, Zaagsma J. Arginase and asthma: novel insights into nitric oxide homeostasis and airway hyperresponsiveness. Trends Pharmacol Sci 2003; 24: 450-455.

27 Morris CR, Poljakovic M, Lavrisha L, Machado L, Kuypers FA, Morris SM Jr. Decreased arginine bioavailability and increased serum arginase activity in asthma. Am J Respir Crit Care Med 2004; 170: 148-153.

28 Di Maria GU, Spicuzza L, Mistretta A, Mazzarella G. Role of endogenous nitric oxide in asthma. Allergy 2000; 55: Suppl. 61, 31-35.

29 Grasemann H, Knauer N, Büscher R, Hübner K, Drazen JM, Ratjen F. Airway nitric oxide levels in cystic fibrosis patients are related to a polymorphism in the neuronal nitric oxide synthase gene. Am J Respir Crit Care Med 2000; 162: 2172-2176.

30 Grasemann H, Storm van's Gravesande K, Büscher R, et al. Endothelial nitric oxide synthase variants in cystic fibrosis lung disease. Am J Respir Crit Care Med 2003; 167: 390-394.

31 Lundberg JO, Farkas-Szallasi T, Weitzberg E, et al. High nitric oxide production in human paranasal sinuses. Nat Med 1995; 1: 370-373. 